\title{
TRATAMIENTO DE LA COQUELUCHE "POR MEDIO DE LOS VUELOS DE ALTURA
}

\author{
Por el Dr. ROBERTO PEDEMONTE ${ }^{\prime} L$ L. \\ Médico-Jife del Servicio de Pediatría d's Hospital Regiond \\ de Puerto Montt. \\ (3 OBSERVACIONES OLINICAS)
}

Mucbas son las terapéticas que han sido usadas para el tratamiento de esta enfermedad que año a año contribuye con sus complicaciones a aumentar las cifras de mortalidad infantil. Todas ellas a excepción de las vacunas en uso tienen como úníco objetivo calmar los accesos convulsivos no siendo sirmpre su acción eficaz.

La presente comunicación tiene por objeto presentar 3 observaciones de enfermos que presentaban accesos de Coqueluche francos y en los cuales se ensayó una nueva terapéutica en la actualidad discutida. Me refiero a los vuelos de altura, que según algunos autores han dado excelentes resultados.

En los casos presentados, el ensayo de esta terapéutica se facilitó por presentarse algunas circunstancias que hicieron fácil su realización. En efecto, encontrábase de paso en este Puerto el Sikorsky "Magallanes" al mando del Comandante Latorre. Por intermedio de un Oficial de la Base Aérea de Chamiza. cuyo hijito sufría de intensos accesos de Coqueluche. obtuvimos la autorización para efectuar esta experiencia terapéutica. Logré, además, reunit dos enfermitos más de mj. clientela particular, que padecian de esta afección.

El vuelo se realizó en perfectas condiciones sobre una altura de 2,800 metros, siendo acompañados los niños por sus madres. La duración del vuelo fué de 1 hora con el descenso que hubo de efectuarse en forma muy lenta para evitar los efectos de los cambios bruscos de prectón atmosférica.

Durante el vuelo, a pesar de la altura, no se observó ningún cambio ni alteración de los enfermitos. A uno de ellos se le controló la presión arterial, observándose un pequeño aumento durante el ascenso y que luego se normalizó. 
Los resultados obtenidos quedan expuestos a continuación:

Observación N.: 1.-A. L. G. Edad: 1 año 4 meses.

Acude a mi consulta ol 18 de enero del presente año por presentar accesos intensos de tos convulsiva desde hace una semana. Se indiza Ferinal y Luminaletas sin obtener reduceión de los accesos, los cuales son cada vez más intensos.

26 de enero.-Vuelo en el Sikorsky. No se observa ninguna alteración del niño durante el vuelo, el cual, por el contrario, se muestra alegre y juega.

Después del vuelo presentó 2 a 3 accesos durante la noche, los cuales se fueron haciendo menos frecuentes hasta desaparocer completamente al $4{ }^{\circ}$ dia de la experiencla.

nbservaclón N." 2.-M. L. D. Edad: 3 años.

Consulta el 22 de enero del prezente año, pcrque desde 5 dias presenta tos en accesos emetizantes. Se diagnostica Coqueluche, prescribiéndose Ferinal y Luminaletas sin obtener calma en los accesos.

26 de enero. Vuolo en Sikorsky.

Antes del vuelo presentaba entre 8 a 10 accesos de tos durante el día acompañados de "reprise".

Después del vuelo presentó alguncs accesos de tos, pero sin "reprise", y en la nophe sólo tuvo un acceso de tos. Al tercer dia la tos desapareció completamente.

Observación N."3.-M. D. Edad: 7 mezas.

Consulta el 22 de enero por presentar desde hace 10 días tos on accesos 7 a 8 diarios $y$ de 3 a 4 en la noche. Se indica hancterapia, poción bromurada y Luminaletas, sin resultado.

26 de enero. Vuelo en el Sikorsky. No presenta durante el vislo ningún acceso ni molestias, a pesar de la altura. Al día siguiente sólo presentó 4 accesos sin "reprise" y uno en la noche. Al 5." dia de la experlencía el niño estaba completamente sano.

Por el éxito obtenido en los tres casos presentados, sería conveniente ampliar estas observaciones, con el fin de obtener conclusiones definitivas al respecto. 
ratronzco Nacionai

de la Infancia

\section{MATERNIDAD "CAROLINA FREIRE"}

\section{Comentario del Movimiento habido en este Estratecimiento}

Por el Dr. EDUARDo KeYMeR y Praf. CARLOS MONCKEBERG

La Maternidad "Carolina Freire" ha continuado funcionando regularmente durante los años 1938 y 1939, con una concurrencia de enfermas que ha sido muy superior a la de años anteriores, lo que nos complace. pues indica que nuestros esfuerzos no han sido perdidos. enfermas.

En el año 1938 fueron atendidos en el Servicio, 1.005

Hubo: 818 partos de término, o sea

162 partos prematuros, o sea $\ldots \ldots \ldots \ldots \ldots . . . . .16,1 \%$

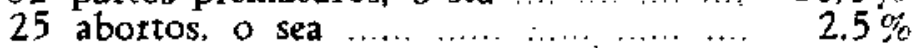

En el año 1939 se atendieron en el Servicio. 1,054 enfermas.

Hubo: 907 partos de término, o sea ….......... $86 \%$

134 partos prematuros, o sea ............. $12,7 \%$

13 abortos. o sea...

Una enferma ingresó mejorađa.

Presentaciones gemelos multiparidad

Tanto en 1938 como en 1939 la proporción entre primiparas y multíparas fué más o menos igual; predominando las primíparas en 1938 y las multíparas en 1939.

Las presentaciones por orden de frecuencia fueron: 
Año 1938

Vértice

Cefálica indiferente

919, o sea el

34 , o sea el

27, o sea el

Nalgas

5, o sea el

$90,3 \%$

Tronco

12, o sea el

$3,4 \%$

$2,7 \%$

$0,51 \%$

Gemelos

Año 1939

Vértice

Cefálica indiferente

971, o sea el 92

Nalgas

39. o sea el

28 , o sea el

$1,2 \%$

Tronco

6, o sea el

2, o sea el

8. o sea el

Gemelos

l

Trillizos

\section{Morbilidad obstétrica}

Tomatemos en cuenta solamente los grandes sindromas que, por su gravedad, merecen una consideración especial:

Annemia aguda obstétrica:

En 1938 hubo

6 casos

En 1939 hubo

6 casos

En todos los casos se practicó la transfusión sanguínea junto al tratamiento de rigot y felizmente no tuvimos que lamentar ninguna pérdida por esta causa.

\section{Eclampsia:}

En 1938 hubo un caso post partum.

En 1939 hubo un caso ante partum.

Eclampsismo:

En 1938 hubo un caso.

En 1939 hubo dos casos. 
Placenta previa:

En 1938 hubo dos casos.

En 1939 hubo ocho casos.

Infecciones puerperales:

En el año 1938 hubo 12 infecciones puerperales, o sea. el $1.2 \%$ de nuestras asistidas presentó esta complicación.

Las diferentes formas de infección fueron:

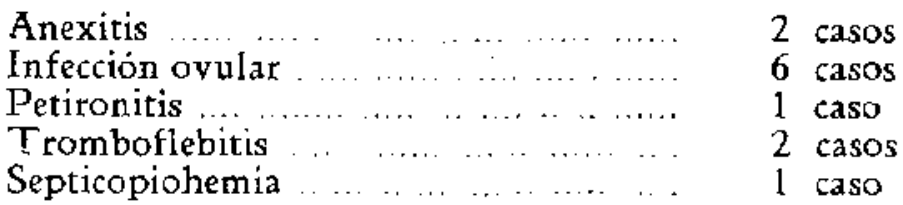

Cinco de las enfermas con infección ovular ingresaron al Servicio con esta complicación y membranas rotas, desde muchas horas antes.

En una, la rotura prematura de la bolsa de aguas fuera del Servicio era muy sospechosa.

El caso de peritonitis Bol. 549, pertenece a una primipara que ingresó con infección amniótica y que después de fra. casar varias maniobras obstétricas se somete a una operación cesárea suprasinfisiaria. La enferma falleció al día siguiente de la intervención.

- El caso de septicopiohemia, Bol. 479, perteriece a una primípara que ingresó con membranas rotas desde hacía 18 horas. y a la que por sufrimiento fetal intenso hubo de aplicarse forceps. La enferma se fué de alta en perfectas condiciones. después de 60 dias de un puerperio accidentado.

El caso de tromboflebitis. Bol. 903, se refiere a una enferma que ingresó con infección ovular y 40 horas de mem. branas rotas. Su parto fué normal y espontáneo y después de un puerperio fébril se fué en perfectas condiciones. El se. gundo caso, Bol. 765, se refiere a una primípara que después de tres horas de expulsión se le practica una aplicación de forceps por sufrimiento fetal, como ésta fracasara, se hace una sinfisiotomia. La enferma se fué de alta en buenas condiciones después de 30 dias de puerperio.

En el año 1939 hubo 8 casos de infección puerperal, o sea, el $0.7 \%$. 
Las diferentes formas de infección fueron:

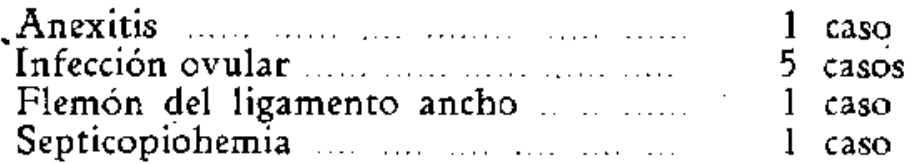

Tres de las enfermas con infección amniótica ingresaron en este estado a la Maternidad. En juna la rotura prematura de la bolsa de aguas fuera del Servicío es dudosa. En una, esta complicación apareció estando la enferma en el Servicio con membranas intactas después de 72 horas de trabajo.

El caso de flemón del ligamento ancho, Bol. 700. corresponde a una enferma que tuvo un parto prematuro de $81 / 2$ meses. con feto macerado.

En el puerperio apareció esta complicación, que evolucionó a la curación, después de drenar el parametrió.

El caso de septicopiohemia, Bol. 506, corresponde a una primípara, que tuvo su parto y puerperio inmediato normales y que reingresa al Servicio 13 días después con hemorragia, en estado anémico. Se le practicó una revisión intrauterina y continuó con un cuadro grave de septicopiohemia. La enferma fué trasladada a su domicilio.

\section{Vicios pelvianos:}

En 1938 hubo 10 peivis generalmente estrechas.

En 1939 hubo 14 pelvis generalmente estrechas.

\section{Mortalidad}

En el año 1938 fallecieron 3 enfermas, o sea, el $0.3 \%$. De éstas, dos fallecieron por causa obstétrica: una por peritonitis post cesárea baja y la otra por shock obstétrico después de una intervención.

Una falleció de una hepıtitis aguda y anemia, ingresando al Servicio en estado muy grave.

En el año 1939 falleció una. enferma. o sea el $0.09 \%$. La causa de muerte fué una embolía pulmonat, después de un parto normal.

\section{Intarvenciones obstétricas}

Tanto en el año 1938 como 1939. la intervención más frecuente fué la aplicación de forceps indicada siempre en pri- 
míparas por suftimiento fetal intenso o por falta de descenso de la presentación, debido a una mala orientación de ella. La sigue en frecuencia la versión interna.

Los casos de estrechez vagino-vulvo perineal los resolvimos por perineotomía o por episiotomia, cuando se trataba de perinés muy cortos.

\section{Operación cesárea:}

En 1938 se practicaron cuatro operaciones cesáreas: unj clásica y tres suprasinfisiatias.

En 1939 se practicaron siete operaciones cesáreas: una clásica y cinco suprasinfisiarias.

Sinfisiotomía:

En 1938 se practicaron cuatro sinfisiotomías, según la técnica de Zárate. Todas se fueron en buenas condiciones. sultados.

En 1939. se practicaron dos sinfisiotomías, con buenos te-

\section{Niños}

En el año 1938 nacieton 980 niños, de los cuales nacieron muertos 13 , o sea, un $1,3 \%$. De éstos, 10 nacieron macenados, y la causa de la muerte fué la lúes, 2 presentaton al nacer procidencia del cordón, y 1 nació en asfixia pálida por circular del cordón.

Murieron en el Servicio, 7 niños, o sea, el $0,7 \%$; la causa de muerte fué en dos casos, la asfixia azul intensa, y én 5 casos la asfixia pálida.

En el año 1939 nacieron 1,041 niños, de los cuales nacieron muertos 11 , o sea, un $1,05 \%$. De éstos 6 nacieron macerados (sífilis congénita). Uno presentó procidencia del cordón. En 4 na pudo establecerse la causa precisa de la muerte.

Murieron en el Servicio 10 niños, o sea, el $0,9 \%$. Causa de muerte:

Asfixia

8 casos

Prematurez

2 casos

\section{Comentario}

Del estudio comparativo entre los años 1935, 1936. 1937. y los años 1938 y 1939, se desprende que el número de 
infecciones puerperales ha disminuído considerablemente; basta mirar el siguiente cuadro:

\begin{tabular}{l} 
Año \\
\hline 36 \\
37 \\
38 \\
39
\end{tabular}

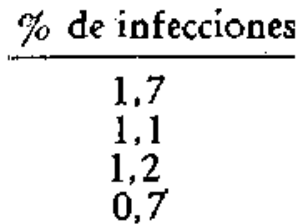

Esta diferencia se acentúa, si restamos los casos que ingresaron infectados desde fuera y en los cuales ninguna responsabilidad cabe al Servicio. Así los porcenta jes bajan de 1,2\% a $0,6 \%$ en 1938 y de $0.7 \%$ a $0,2 \%$, en 1939 .

También el indice de mortalidad general ha disminuido, como puede verse en el siguiente cuadro:

\begin{tabular}{r} 
Año \\
\hline 35 \\
36 \\
37 \\
38 \\
39
\end{tabular}

$\%$ de mortalidad

1,03

0,3

0,2

0,3

0,09

Respecto al recién nacido, debemos recalcar una disminución franca en la mortalidad y mortinatalidad,. como puede verse en el siguiente cuadro:

\begin{tabular}{|c|c|c|}
\hline AẼO & Nacidos meertos & Muertosen el Servicio \\
\hline $\begin{array}{l}35 \\
36 \\
37\end{array}$ & $\begin{array}{l}4,4 \% \\
1,6 \% \\
1,5 \% \\
1,3 \% \\
1,05 \%\end{array}$ & $\begin{array}{l}0 \% \\
1,4 \% \\
1.6 \% \\
0,7 \% \\
0,9 \%\end{array}$ \\
\hline
\end{tabular}

